\title{
THREE-DIMENSIONAL NUMERICAL STUDY OF THERMAL EXCHANGES IN DIFFERENT GEOMETRY SECTIONS OF MINI- CHANNELS USING THREE DIFFERENT NANOPARTICLES
}

\author{
Kamel Chadi ${ }^{1 *}$, Nourredine Belghar ${ }^{l}$, Belhi Guerira $^{l}$, Aissam Messaoudi ${ }^{2}$ \\ ${ }^{1}$ Laboratory of Materials and Energy Engineering, University of Mohamed Khider \\ Biskra, Algeria \\ ${ }^{2}$ Abbes Laghrour University of Khenchela, Algeria
}

Received 04.12.2019

Accepted 08.04.2020

\begin{abstract}
In the present work, we have studied the thermal exchanges of different geometry sections of mini-channels of a cooler numerically. Particularly, we have chosen a mini channels cooler copper for cooling an electronic chip IGBT. In our simulation of threedimensional (3D), we have compared the numerical results for the different forms of the proposed mini-channels and the three different types of nano-fluids by using the $\mathrm{Cu}$ water, the $\mathrm{Ag}$-water, and the Diamond-water with a volume fraction of $0.02 \%$. The numerical results are obtained by choosing a Reynolds number (Re) between 100 and 900 and considering that the flow regime is stationary.

The simulation was performed using commercial software, ANSYS-Fluent 15.0. The results obtained show that the increase of the exchange surface between the walls of the mini channels and the cooling fluid makes increases the heat exchange coefficient and the improvement of the maximum junction temperature of the electronic chip IGBT with the increase of the Reynolds number.

The choice of nanoparticles has considerable effects on improving the heat transfer and the maximum junction temperature of the chip IGBT.
\end{abstract} fluent.

Keywords: heat exchange; mini-channels; numerical simulation; nanofluid;

\section{Introduction}

Temperature is an important factor in the performance of the electronic component. This temperature can be high enough to reduce in a significant manner the life of the component. To ameliorate this temperature, it is necessary to ameliorate the

*Corresponding author: Kamel Chadi, chadikamel_dz@yahoo.fr 
heat exchanger and the cooling method of components. The improvement of the heat transfer is directly related to several factors such as the thermal properties of the used materials and fluids, the Reynolds number [1], the geometrical shapes and their dimensions. Among the work in this domain, Bakhshi et al. [2] studied the effect of changes in geometric parameters of a laminar flow through the trapezoidal microchannels on heat transfer and fluid flow numerically. Also, they studied the heat flux rate with hydraulic diameter variations. They concluded that the maximum and minimum heat transfer rate occurs in a trapezoidal microchannel with $75^{\circ}$ and $30^{\circ}$ internal's, respectively. Mohebbi et al. [3] studied the effect of the location of a heat source on natural convection in a $\mathrm{C}$-formed enclosure. They used water- $\mathrm{Al}_{2} \mathrm{O}_{3}$ nanofluid with different solid volume fractions (0-0.05) and with different Rayleigh numbers (103-106). Among the results, they found that the biggest value of the Nusselt number is achieved when the heat source is located within the horizontal cavity.

In this context, Wang et al. [4] studied the influence of the geometric characteristics on the heat transfer performance and liquid flow of the triangular, rectangular, and trapezoidal cross-sectional micro-channel numerically. The results confirmed that the form and geometric parameters of micro-channel have a remarkable effect on the liquid flow and heat exchanger characteristics of a microchannel heat sink. Tawk et al. [6] developed a numerical and experimental study of a cooling system for power electronics based on the setting in motion of a heat-conducting fluid noting the importance of the choice of the material constituting the cooler with the advantages brought by liquid metal. Nasrin et al. [5] studied the effect of nanofluids on the heat transfer and cooling system of the photovoltaic thermal (PVT) performance. They concluded that the photovoltaic thermal system worked by nanofluid is more effective than a water-based photovoltaic thermal system. Qi et al. [7] used $\mathrm{TiO}_{2}$-water nanofluid, with different volume fractions, to investigate the stabilities of the natural convective heat transfer characteristics and thermophysical properties. They proved that the heat transfer could be enhanced by $34.2 \%$ with the increase of mass concentration of nanoparticle at the largest cavity ratio and the lowest heating power. They also indicated that the thermal conductivities of $\mathrm{TiO}_{2}-\mathrm{H}_{2} \mathrm{O}$ nanofluids could be improved by $5.23 \%$. Wang et al. [8] studied the heat transfer of miniature loop heat pipe by using water-copper nanofluid with different volume concentrations numerically. It was found that the temperature differences of miniature loop heat pipe using nanofluid are always lower than those of miniature loop heat pipe using de-ionized water for an input power of $25 \mathrm{~W}$.

Tuckerman and Pease [9] determined the performances of cooling of the electronic components with the aid of liquid flow through micro-channels without change of stage. They fabricated an interchange of $100 \mathrm{~mm} 2$ in silicon. These results showed that the heat transfer coefficient of laminar flow through the micro-channels is more important than the heat transfer coefficient across the channels of conventional size. Wu and Cheng [10] conducted experimental research on the convective heat exchanger and friction coefficient of deionized water in silicon trapezoidal microchannels with different geometrical configurations, surface roughness and different hydraulic diameters. They showed that the coefficient of friction depends considerably on the different geometrical parameters increasing with the roughness of the wall. On the other hand, Nonino et al. [11] developed an analytical study of the conjugate conduction/convection heat transfer in cross-liquid micro heat exchangers. It was showed that the increase of the microchannels number per layer yields increases relative pressure drop. 
Belahmadi et al. [12] investigate the entropy generation and the heat transfer of a $\mathrm{Cu}-\mathrm{H}_{2} \mathrm{O}$ nano-fluid in a vertical channel by using fluent software and a simple algorithm. Their results showed that the increase of Grashof and Reynolds numbers and volume concentration of nanoparticles reduces the entropy generation and improves the heat transfer. Khaleduzzaman et al. [13] presented an analytical study of the thermal performance improvement of three nano-fluids $\left(\mathrm{Al}_{2} \mathrm{O}_{3}-\mathrm{H}_{2} \mathrm{O}, \mathrm{CuO}-\mathrm{H}_{2} \mathrm{O}, \mathrm{SiC}-\mathrm{H}_{2} \mathrm{O}\right)$ for a copper rectangular microchannel heat sink for electronic device cooling. They concluded that the $\mathrm{CuO}-\mathrm{H}_{2} \mathrm{O}$ nano-fluid is the most appropriate for the cooling of electronics components among the three nano-fluids.

Abed and Khalil [14] studied the heat transfer and liquid flow in different forms of micro-channels. They concluded that the Nusselt number and convective heat transfer coefficient increase with the increase of the Reynolds number. They also confirmed that the micro-channels with two notches form to present the convective heat transfer coefficient and Nusselt number $(\mathrm{Nu})$ with the highest value, compared to the microchannels with straight rectangular form and micro-channels with six and four notches form. Gherasim et al. [15] presented numerical simulations for a radial fluid flow cooling system with an $\mathrm{Al}_{2} \mathrm{O}_{3}-\mathrm{H}_{2} \mathrm{O}$ nanofluid flow. They indicated that the addition of $\mathrm{Al}_{2} \mathrm{O}_{3}$ nanoparticles to the water (base fluid) enhances the heat exchanger performance. Also, Khanlari et al. [16] studied the heat transfer performance in the plate type heat exchangers by using the $\mathrm{TiO}_{2} / \mathrm{H}_{2} \mathrm{O}$ as a nano-fluid. They showed that the $\mathrm{TiO}_{2} / \mathrm{H}_{2} \mathrm{O}$ nanofluid improved the heat transfer coefficient.

Among recent studies in the field of improved heat transfer, Kumar and Pawan Kumar Singh [17] improved the heat performance of a mini-channel using a new inletoutlet approach. Among their observation, inlet-outlet arrangement with inflow angle equal to $105^{\circ}$ has the smallest value of maldistribution factor, whereas conventional inletoutlet arrangement has the biggest value of maldistribution factor. Also, they founded that the maximum heat sink base temperature has been observed in the conventional arrangement. Indeed, the lowest heat sink base temperature has been founded in the proposed arrangement with an inflow angle equal to $105^{\circ}$. Also, a temperature drop of 2 ${ }^{\circ} \mathrm{C}$ has been observed with the proposed flow arrangement. Then, they concluded that the thermal resistance decreases with the rate of the fluid flow for all arrangements. Bezaatpour and Goharkhah [18] studied the effect of porous media on the convective heat transfer and pressure loss of magnetite-water nanofluid in rectangular and circular channel heat sinks numerically. They founded that also, without porous media, the thermal transfer is lower for the circular channel heatsink than the rectangular channel heatsink. While the thermal transfer from the circular channel overtakes that of the rectangular channel in the presence of porous media. Also, the thermal transfer concerning the liquid flow in clear heat sinks increases with the volume concentration and decreases with the rate of liquid flow and porosity.

On the other hand, Saeed and Kim [19] investigated numerically and experimentally the heat exchanger enhancement characteristics using four different channel configurations of a mini-channel heat sink, and with three different volume fractions of nanoparticles $\mathrm{Al}_{2} \mathrm{O}_{3}$ in base fluid (water). They observed an enhancement of $24.9 \%, 27.6 \%$, and $31.1 \%$ in the heat transfer coefficient of the heat sink with fin spacing of $1.5 \mathrm{~mm}, 1 \mathrm{~mm}$, and $0.5 \mathrm{~mm}$ respectively. They also observed that the enhancement factor increases by dreading the fin spacing of the liquid flow channel at the same value of volume fraction and rate of coolant flow. Also, Ramin et al. [20] studied the effect of 
height, inlet velocity, attack angles and rib's arrangement on the overall performance of mini-channel. They concluded that the heat exchanger performance increases with the increase of the rib's height and the inlet velocity. Indeed, the heat transfer efficiency was improved with the attack angles of $60^{\circ}$. They also concluded that mini-channels with both trapezoidal and rectangular ribs have the best results for thermal transfer and liquid flow performance in comparison to a mini-channel with rectangular ribs.

The objective of the present paper is to study and compare the thermal exchange between the different forms of the proposed mini-channels of the cooler size $(21 \mathrm{~mm} \mathrm{x}$ $21 \mathrm{~mm} \times 3.5 \mathrm{~mm}$ ) using three types of nanofluids to obtain a better cooling of the electronic chip IGBT $1200 \mathrm{~V} 75 \mathrm{~A}$; also, for the improvement of the heat transfer between the walls of the min-channels and the cooling fluid.

Thermo-physical properties of the nano-fluid

The calculation of the thermo-physical properties of the nanofluids used in our work are written in this section [21,22].

The Maxwell-Garnetts model approximates the thermal conductivity of the nanofluid:

$$
K_{n f}=\frac{K_{s}+2 K_{f}-2 \varphi\left(K_{f}-K_{s}\right)}{K_{s}+2 K_{f}+\varphi\left(K_{f}-K_{s}\right)} K_{f},
$$

Where $\varphi$ is the volume fraction, $K_{s}$ is the thermal conductivity of the nanoparticles, and $K_{f}$ and $K_{n f}$ represent the thermal conductivity of the base fluid (water) and nanofluid.

The dynamic viscosity of the nanofluid is given as:

$$
\mu_{n f}=\frac{\mu_{f}}{(1-\varphi)^{2.5}}
$$

Where $\mu_{f}$ is the dynamic viscosity of the water.

The density of the nanofluid is given as:

$$
\rho_{n f}=(1-\varphi) \rho_{f}+\varphi \rho_{s}
$$

Where $\rho_{f}$ is the density of the water, $\rho_{s}$ is the density of the nanoparticles

The heat capacity of the nanofluid is expressed as given by Khanafer et al. [23]:

$$
\left(\rho C_{p}\right)_{n f}=(1-\varphi)\left(\rho C_{p}\right)_{f}+\varphi\left(\rho C_{p}\right)_{s}
$$

Where $C_{p f}$ is the heat capacity of the water, $C_{p s}$ is the heat capacity of the nanoparticles.

The thermo-physical properties of pure fluid and nanoparticles are presented in Table 1 [24]. 
Table 1. Thermo-physical properties of the water and nanoparticles.

\begin{tabular}{lllll}
\hline Material & $\begin{array}{l}\rho \\
(\mathrm{kg} / \mathrm{m} 3)\end{array}$ & $\begin{array}{l}\mathrm{Cp} \\
(\mathrm{J} / \mathrm{kg} \cdot \mathrm{K})\end{array}$ & $\begin{array}{l}\mathrm{K} \\
(\mathrm{W} / \mathrm{m} \cdot \mathrm{K})\end{array}$ & $\begin{array}{l}\mu \\
(\mathrm{kg} / \mathrm{m} \cdot \mathrm{s})\end{array}$ \\
\hline Water & 997 & 4187 & 0,613 & 0,00085 \\
Cu nanoparticles & 8933 & 385 & 401 & - \\
Ag nanoparticles & 10500 & 235 & 429 & - \\
Diamond nanoparticles & 3500 & 509 & 2300 & - \\
\hline
\end{tabular}

\section{Geometrical system}

The geometrical system is represented in Fig. 1 by the commercial ANSYS fluent. It is based on the mini-channels cooler. Due to the symmetry configuration, we have considered only half of the cooler, as presented in Fig. 2.

The geometry of the first case was used in an experimental and numerical study of a cooling system of electronic components by a liquid metal [6]. This cooler is formed of 10 channels and 11 fins. The power of the chip IGBT $1200 \mathrm{~V} 75 \mathrm{~A}$ is equal to $130 \mathrm{~W}$ with thermal insulation on all the outside faces of the cooler. The inlet temperature of the nano-fluid in the cooler in all cases is equal to $\mathrm{T}=298.15 \mathrm{~K}$.

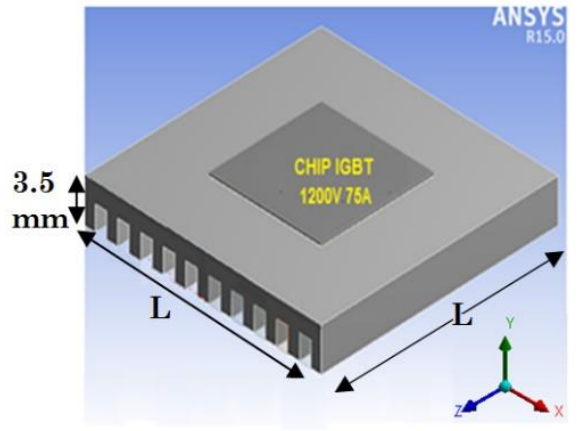

Fig. 1. CAD model of the mini-channels cooler.

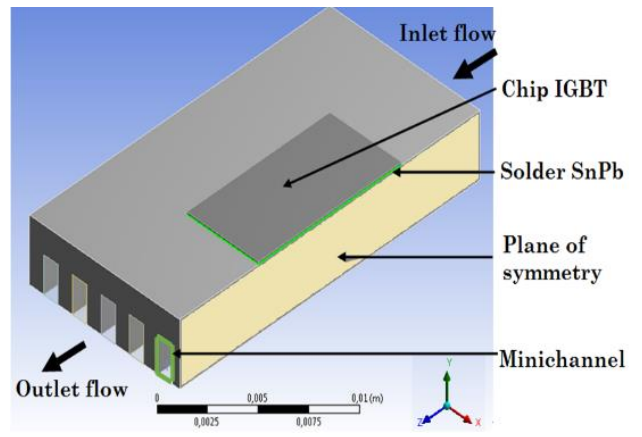

Fig. 2. Computational domain of mini-channels cooler.

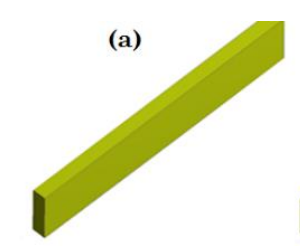

(d)

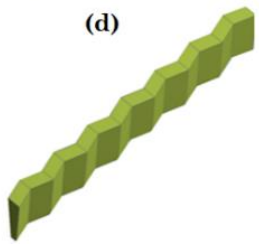

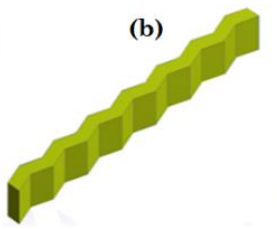

(e)

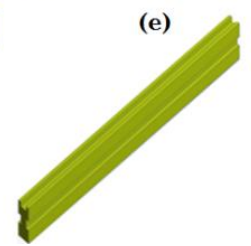

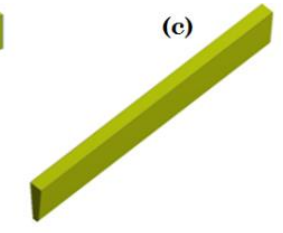

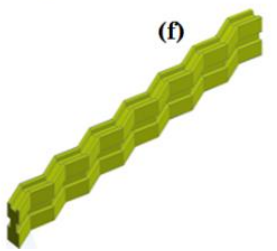

Fig. 3. Studied cases of the mini-channel coolers: (a) case 1, (b) case 2, (c) case 3, (d) case 4, (e) case 5, (f) case 6. 


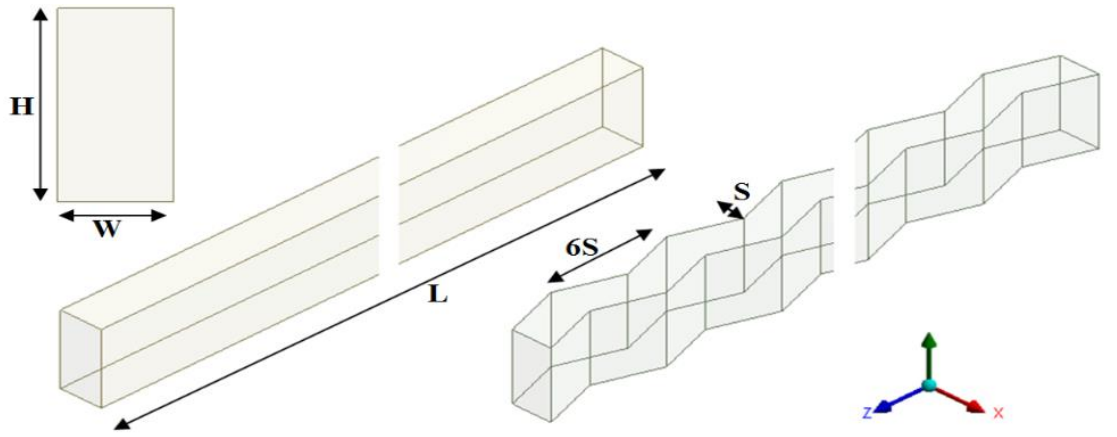

(a)

(b)
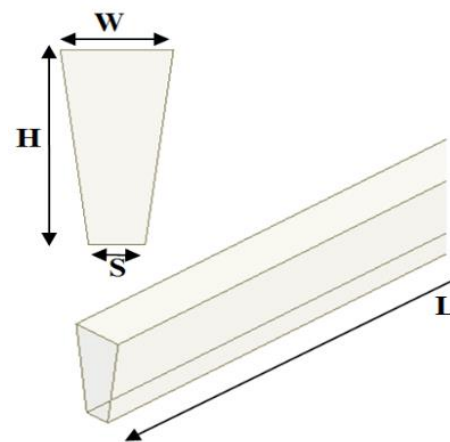

(c)
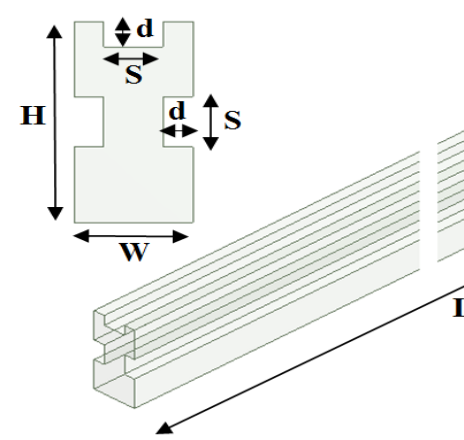

(e)

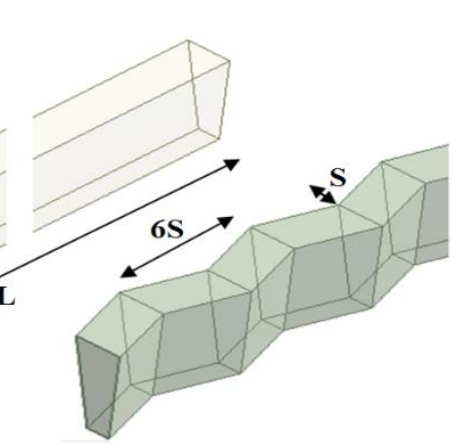

(d)
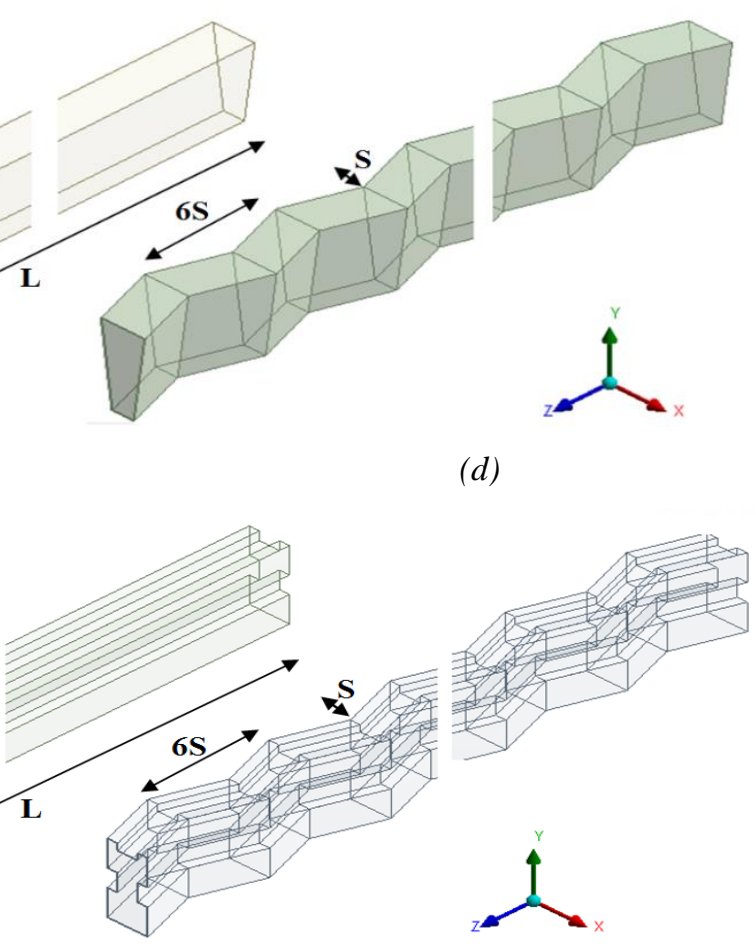

(f)

Fig. 4. Geometrical dimension of the studied cases: (a) case 1, (b) case 2, (c) case 3, (d) case 4, (e) case 5, (f) case 6. 
Table 2. The dimension of the studied cases.

\begin{tabular}{llllll}
\hline Cases & $\mathrm{H}(\mathrm{mm})$ & $\mathrm{W}(\mathrm{mm})$ & $\mathrm{L}(\mathrm{mm})$ & $\mathrm{S}(\mathrm{mm})$ & $\mathrm{d}(\mathrm{mm})$ \\
\hline Case 1 and case 2 & 2 & 1 & 21 & $/$ & $/$ \\
Case 3 and case 4 & 2 & 1 & 21 & 0.50 & $/$ \\
Case 5 and case 6 & 2 & 1 & 21 & 0.50 & 0.25 \\
\hline
\end{tabular}

\section{Mathematical formulation}

In this study, we assumed that the flow is stationary. The three nano-fluids considered are the $\mathrm{Cu}-\mathrm{H}_{2} \mathrm{O}$, Diamond $-\mathrm{H}_{2} \mathrm{O}$, and $\mathrm{Ag}-\mathrm{H}_{2} \mathrm{O}$. These nano-fluids are supposed to be incompressible and the thermophysical characteristics of nanofluids are constant, except for the variation of the density, which is estimated by the Boussinesq hypothesis. The heat transfer by radiation is considered negligible.

The boundary conditions are considered as follows:

- the speed of the fluid inlet is constant;

- zero pressure at the outlet of the mini channels;

- the thermal flux of the chip is constant in the superior face of the cooler;

- the velocity components of the fluid at the level of the channel wall are equal to zero;

- the impact of the body force and the viscosity dissipation is neglected.

At the solid/nano-fluid interface, the continuity of the flux can be written as follows:

$$
\left.K_{s} \frac{\partial T}{\partial n}\right|_{w}=\left.K_{n f} \frac{\partial T}{\partial n}\right|_{w}
$$

Where $T$ is the temperature, $\mathrm{w}$ is the outer normal coordinate at the interface between the wall and the fluid.

The numerical model is governed by the equation of conservation of mass, momentum equation, energy conservation equation, and equation of the solid $[25,26]$.

The continuity equation is written as follows:

$\nabla\left(\rho_{n f} V_{m}\right)=0$

Where $V$ is the velocity.

The momentum equations are written as follows:

$$
\nabla\left(\rho_{n f} V_{m} V_{M}\right)=-\nabla P+\nabla\left(\mu_{n f} \nabla V_{m}\right)
$$

Where $P$ is the pressure.

The energy equation is written as follows:

$$
\nabla\left(\rho_{n f} C_{p} V_{m} T\right)=\nabla\left(K_{n f} \nabla T\right)
$$


The heat conduction through the solid wall can be written as follows:

$$
0=\nabla\left(K_{s} \nabla T_{s}\right)
$$

The hydraulic diameter is defined as the ratio of the cross-sectional area over the wetted parameter and it is calculated as follows [27]:

$$
D_{h}=\frac{4 \cdot A_{c}}{p_{c}}
$$

Where $A_{c}$ is the cross-sectional area of mini-channel, $P_{c}$ is the perimeter of mini-channel

The heat transfer coefficient is then calculated using the general equation [25]:

$$
h=\frac{N u K_{n f}}{D_{h}}
$$

Where $D_{h}$ is the hydraulic diameter of mini-channel, $N_{u}$ is the Nusselt number $\left(N_{u}=q " D_{h} / K \Delta T\right), q$ "is the heat flux $\left(\mathrm{W} / \mathrm{m}^{2}\right)$.

The Reynolds number is defined as [27]:

$$
R e=\frac{\rho_{n f} V D_{h}}{\mu_{n f}}
$$

\section{Validation of the results}

To validate our numerical results, we choose to compare the results obtained by our numerical simulations with those found by Tawk et al. [6]. Fig. 5 presents the validation of our simulation for the variation of the surface temperature according to the different values of fluid flow compared with experimental and numerical results of Tawk et al. [6]. 


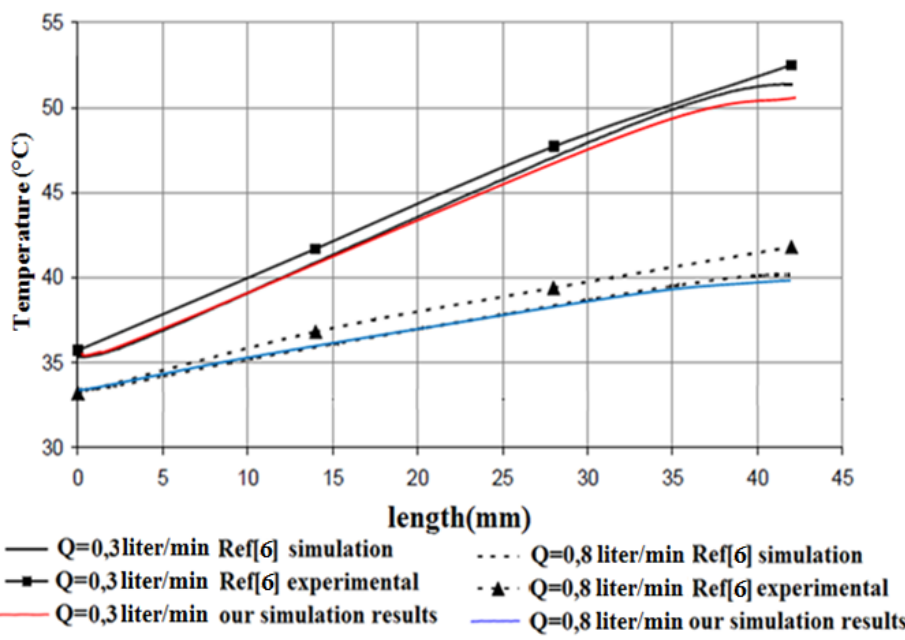

Fig. 5. Variation of the temperature for different values of mass flow ( $Q$ is the mass flow, liter/min).

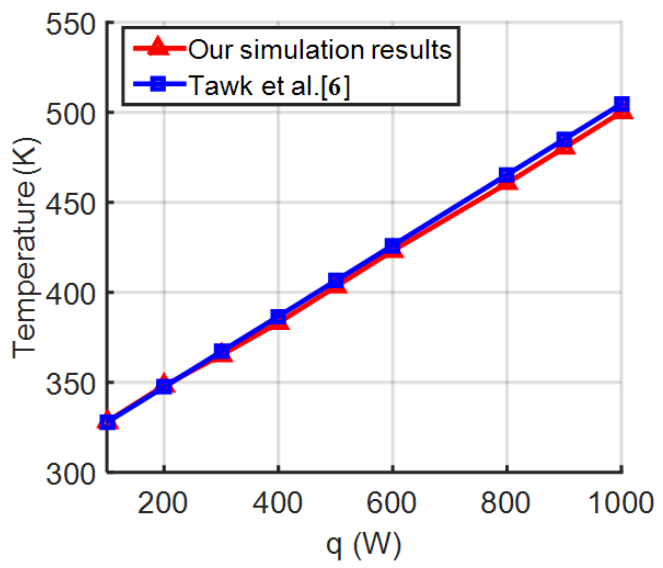

Fig. 6. Evolution of the temperature according to the power dissipated in the chip ( $q$ is the power dissipated in the chip).

Fig. 6 presents a comparison between the numerical results and the anterior results [6] in terms of the evolution of the maximum temperature of the chip as a function of the power dissipated. In this case, we have considered the copper cooler and the water as a coolant.

From these results, it is clear that the temperature increases as a linear Curve with the length. In these conditions, the maximum value of the temperature is equal to $\mathrm{T}=53{ }^{\circ} \mathrm{C}$. These results show a good agreement with the results of Tawk et al. [6]. In these conditions, the gap between numerical and experimental results is about $5 \%$. These results confirm the validity of the numerical method. 


\section{Results and discussions}

Independent of the mesh

Fig. 7 shows the variation of the temperature of the upper surface of the minichannels cooler corresponding to the first case, along the symmetry plane for the different applied meshes. From these results, we confirm that the solution is independent of the mesh.

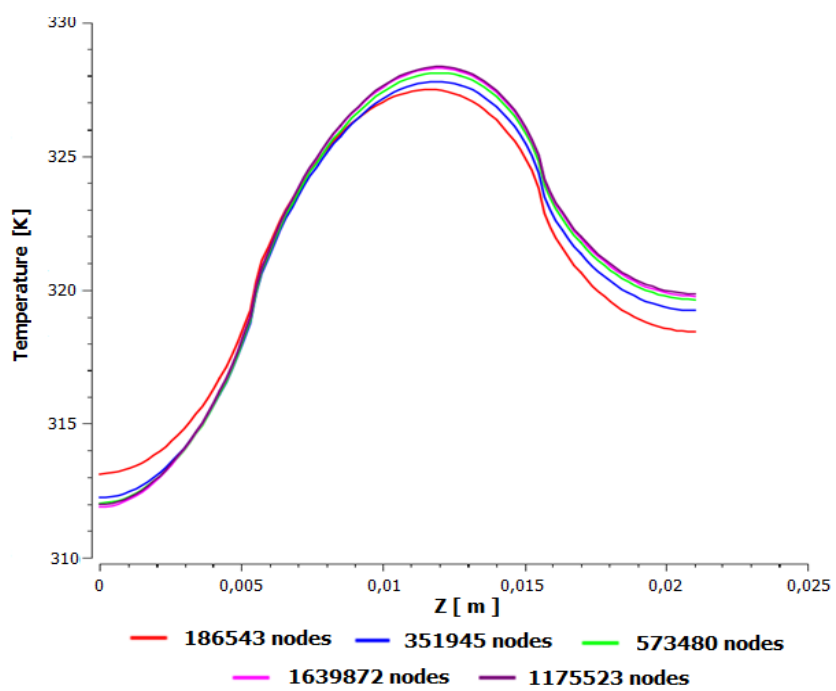

Fig. 7. Influence of the mesh on the temperature of the upper surface of the cooler.

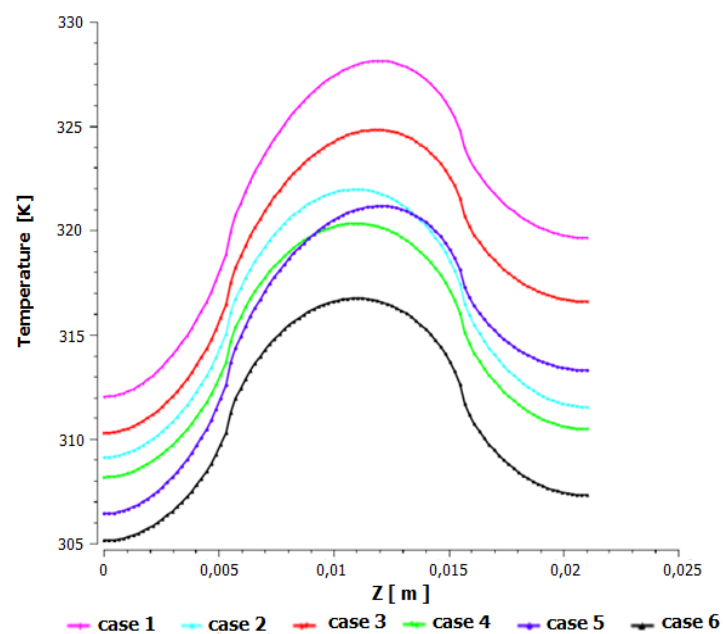

Fig. 8. Temperature of the upper surface of cooler in 6 cases for $R e=500$, the power is $130 \mathrm{~W}$. The inlet temperature is equal to $298.15 \mathrm{~K}$ and for $\mathrm{Cu}$-water nanofluid.

Evolution of the temperature of the upper surface of the mini-channel cooler for all cases 
Fig. 8 shows the evolution of the temperature of the upper surface of the minichannel cooler along the symmetry plane for the different cases of the considered mini channels cooler. From these results, it has been noted that the values of the temperature of the upper surface of the mini-channel cooler of the sixth case are inferior in comparison with other cases.

Evolution of the junction temperature value of the chip in the function of the Reynolds number

Fig. 9 shows the evolution of the junction temperature value of the chip IGBT 1200 $\mathrm{V} 75 \mathrm{~A}$ in the function of the Reynolds number. According to these results, the junction temperature decreases substantially for all cases of the mini channels of the cooler when the Reynolds number $(R e)$ increases. The chip IGBT presents a high temperature for the lowest values of Reynolds number $R e$ and minimum temperature for the highest values of $R e$. Indeed, it is clear that the maximum junction temperature of the chip in the minichannel cooler of the sixth case is lower than that in the other cases and the used three nanoparticle types. According to these results, it has been noted that the nano-fluid is more effective in reducing the temperature of the chip among the three coolants with diamond- $\mathrm{H}_{2} \mathrm{O}$.

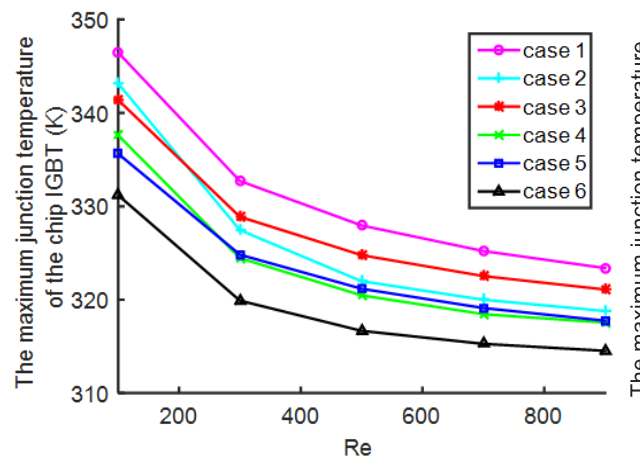

(a)

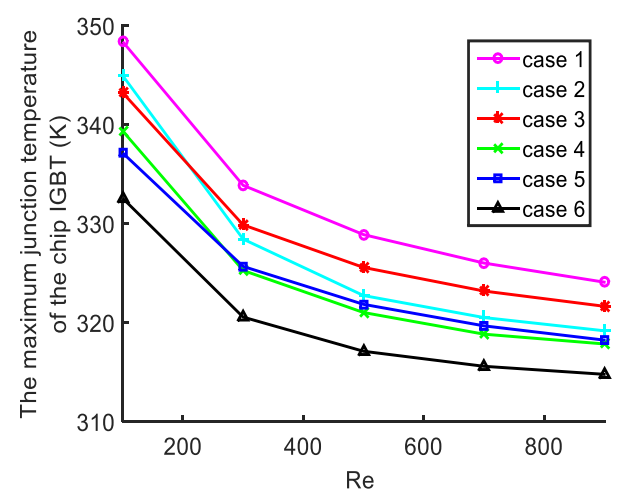

(c)

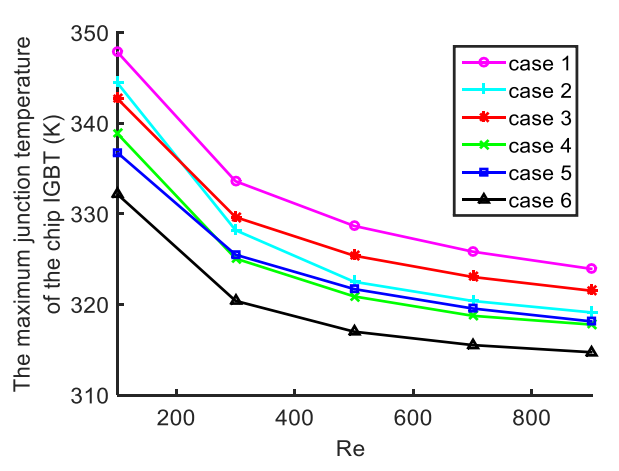

(b)

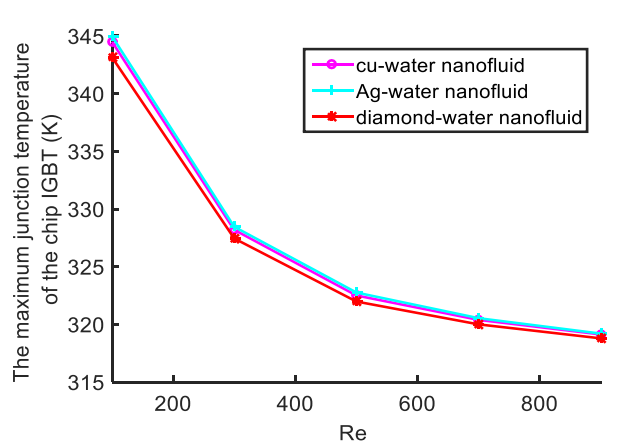

(d) 


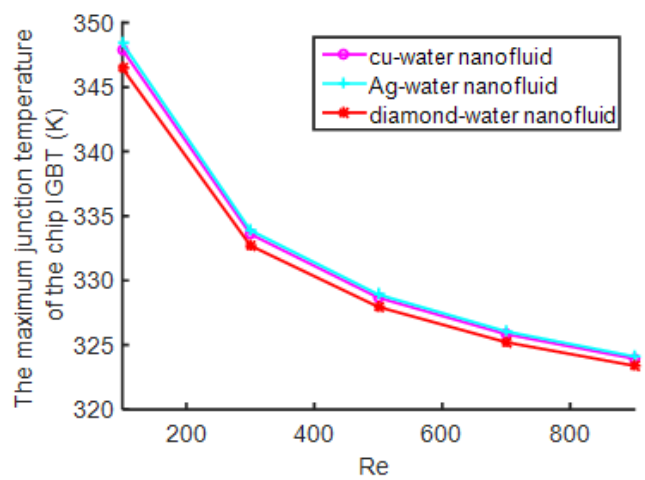

(e)

Fig. 9. Variation of the maximum temperature obtained from the IGBT chip for a volume concentration equal to 0.02 for various types of nanofluids: (a) Diamond-water, (b) Cu-water, (c) Ag-water, and different cases: (d) case 2, (e) case 1.

Distribution of the temperature in the surface of the chip for all cases

Fig. 10 shows the distribution of the temperature in the surface of the chip IGBT, the plane of symmetry and in the upper surface of the cooler for a Reynolds number equal to $R e=500$, and $\mathrm{Cu}-\mathrm{H}_{2} \mathrm{O}$ nano-fluid with a volume faction equal to $\varphi=0.02$. From these results, the value of the maximum junction temperature of the chip and the maximum temperature of the upper surface of the cooler in the first case is the highest $\left(T_{\text {max chip }}=\right.$ $328 \mathrm{~K}$ ) compared with other cases. However, the maximum temperature of the upper surface of the cooler and the maximum junction temperature of the chip IGBT in the sixth case are the lowest than the other cases. This difference of temperature confirms that when the surface area of the exchange increase between the walls of the mini channels of the cooler and nanofluids, the maximum junction temperature of the chip decreases. This decrease improves the absorption of the heat through the fins of the cooler. 

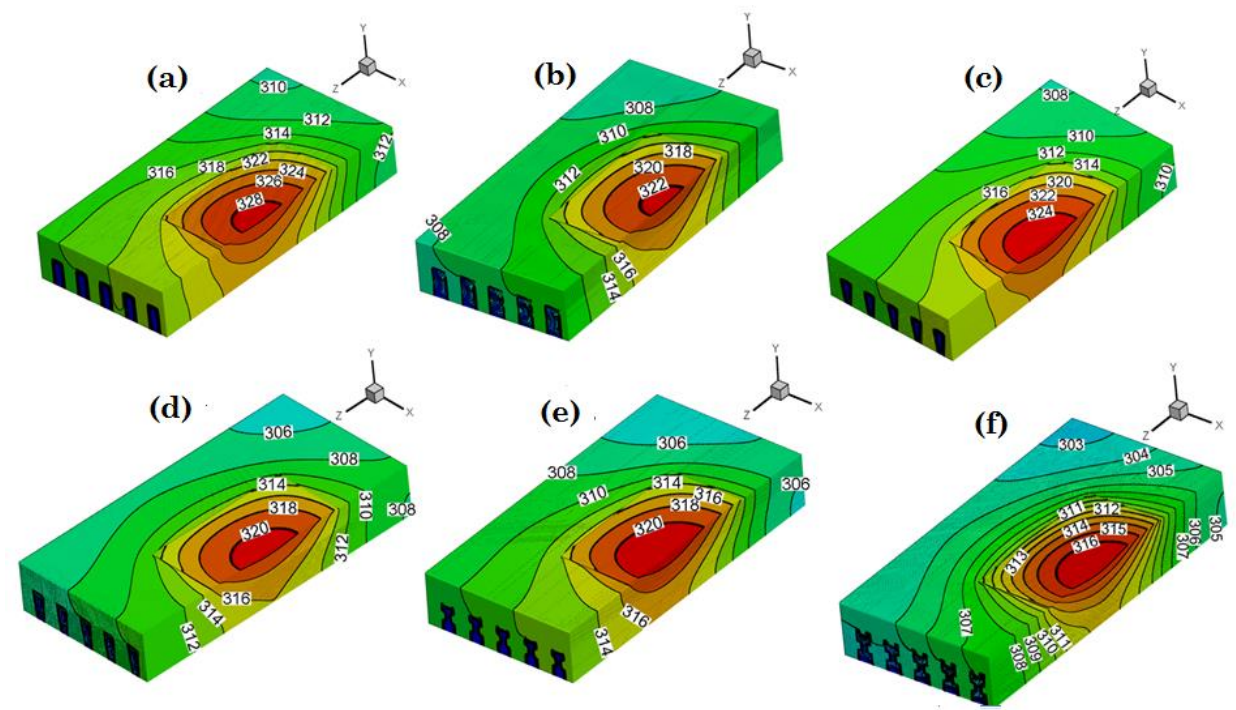

Fig. 10. Distribution of the temperature in the surface of the chip IGBT and the surfaces of the mini channels of the cooler for $\mathrm{Re}=500$, and $\mathrm{Cu}$-water nanofluid (volume fraction $\varphi=0.02$ ): (a) case 1, (b) case 2, (c) case 3, (d) case 4, (e) case 5, (f) case 6.

Evolution of the average heat transfer for all cases

Fig. 11 shows the average heat transfer coefficient calculated as a function of the Reynolds number for a volume fraction of 0.02. According to these results, the average heat transfer coefficient is proportional to the Reynolds number varying from 100 to 900 . Comparing with the mini-channel near the symmetry for each case, the mean heat transfer coefficient values of the mini-channel in the sixth case presents the highest value by comparing it with the other cases. 


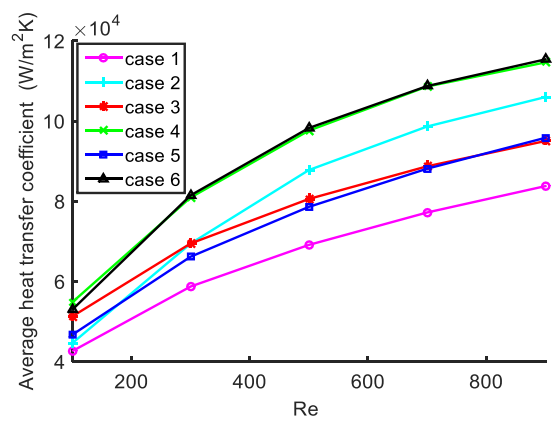

(a) Diamond-water nanofluid

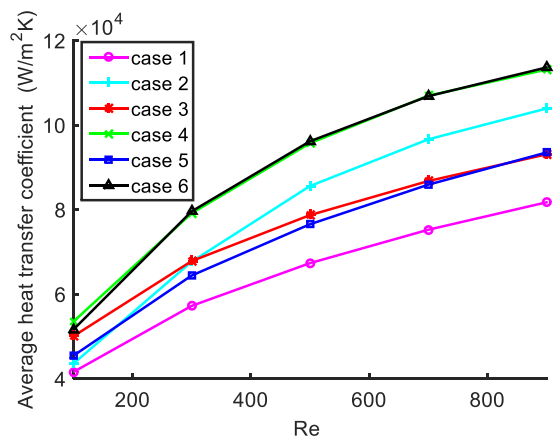

(c) Ag-water nanofluid

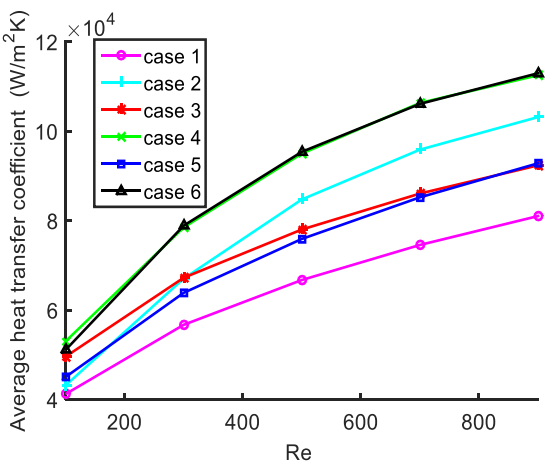

(b) Cu-water nanofluid

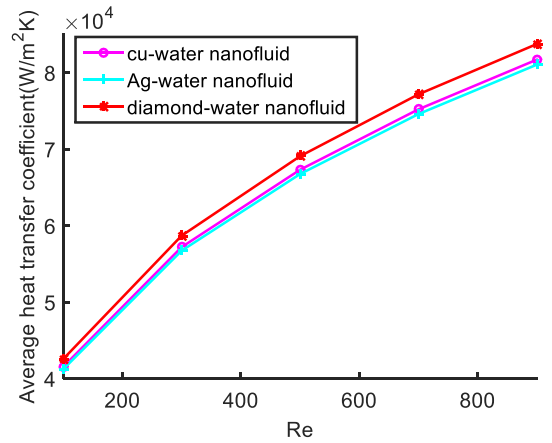

(d) Case 1

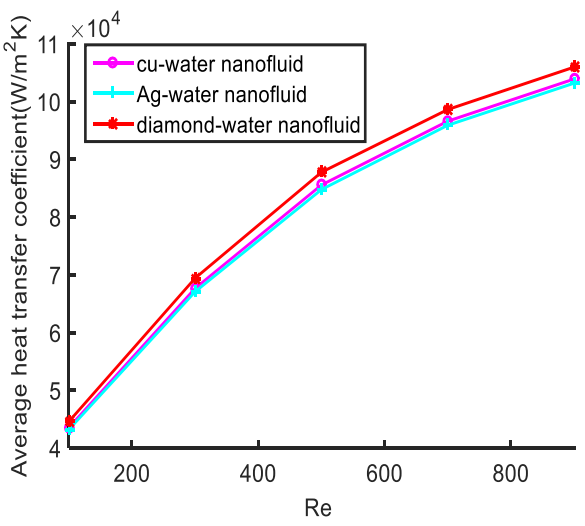

(e) Case 2

Fig. 11. Average heat transfer coefficient for a volume concentration qual 0.02 for various types of nanofluids: $(a),(b),(c)$, and different cases: $(d),(e)$. 
Fig. 12 illustrates the variation of the average heat transfer coefficient as a function of the range of volume concentration varying from $0.01 \%$ to $0.04 \%$ of the copper nanoparticle. From these results, the average convective heat transfer coefficient increases with the increase of the volumetric fraction of the solid for the value of the constant speed equal to $0.34 \mathrm{~m} / \mathrm{s}$ and corresponding to a Reynolds number equal to $R e=$ 500 .

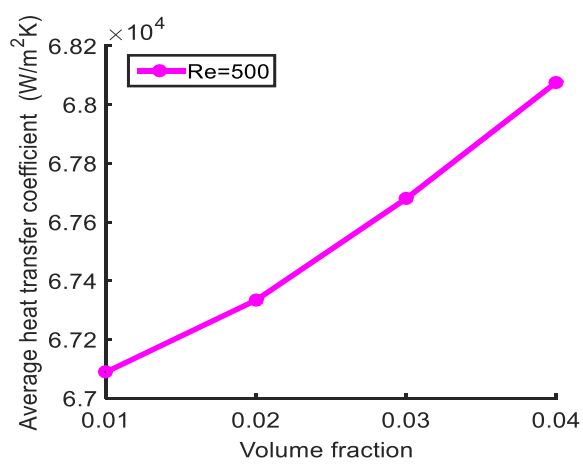

Fig. 12. Variation of the average heat transfer coefficient as a function of the volume concentration.

Influence the nanoparticle diameter on the heat transfer coefficient and the temperature of the chip

From Fig. 13, it is found that the nanoparticle diameter has a considerable effect on the convective heat transfer coefficient and the temperature of the chip IGBT. This effect appears when the size of the nanoparticle decreases. In these conditions, the chip temperature decreases and the transfer coefficient increases.

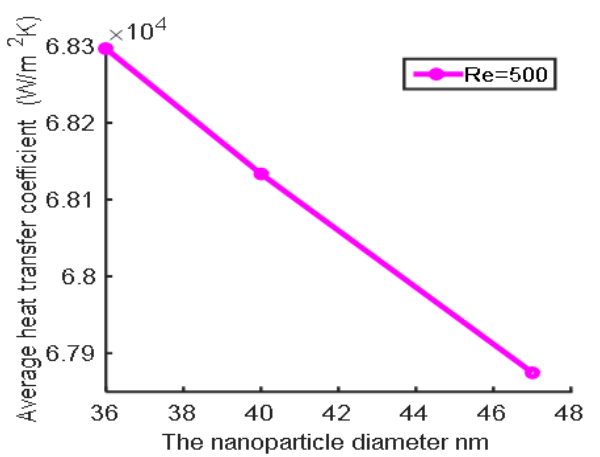

(a)

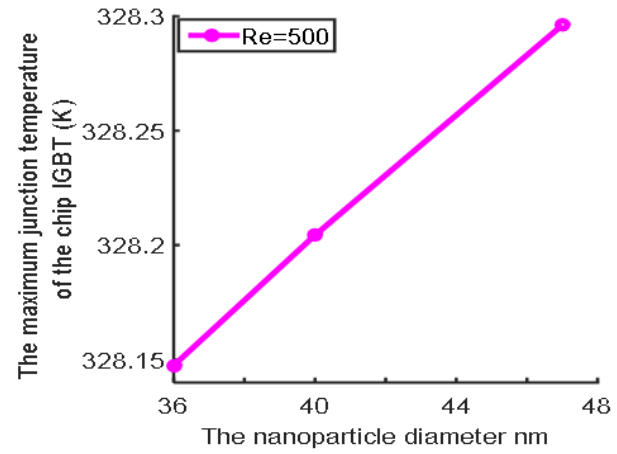

(b)

Fig. 13. (a) The effect of the nanoparticle diameter on the average heat transfer coefficient and (b) the maximum junction temperature of the chip IGBT for the first case for $\mathrm{Cu}$-water nanofluid (volume fraction=0.02) and $\mathrm{Re}=500$. 


\section{Conclusion}

In the present work, we have studied the thermal exchange of different geometry sections of mini-channels numerically by using the commercial software ANSYS-Fluent 15.0. From the obtained results, for the different mini channels, it has been found that in the Reynolds number ranging from 100 to 900 , the mini-channel cooler in the sixth case gave a transfer improvement over other cases, and also improvement of the maximum temperature value of junction of the electronic chip is also observed. In these conditions, the types of nanoparticles also have considerable effects on the improvement of the heat transfer especially with the decrease of the nanoparticle diameter and with the increase of volumetric fraction. In this study, we found that the best heat transfer fluid among the nanofluids studied is the nanofluid that contains the diamond nanoparticles.

These results will be used for the design and improvements of the mini channels.

\section{References}

[1] V. Farhad, M. Mohadeseh: J Mechanical Engineering, 61 (2015) 669-679.

[2] H. Bakhshi, E. Khodabandeh, O. Akbari, D. Toghraie, M. Joshaghani, A. Rahbari: Int J Numerical Methods for Heat and Fluid Flow, 29 (2018) 1680-1698.

[3] R. Mohebbi, M. Izadi, A.J. Chamkha: J Physics of Fluids, 29 (2017) 122009.

[4] H. Wang, Z. Chen, J. Gao: Applied Thermal Engineering 107 (2016) 870-879.

[5] R. Nasrin, M. Hasanuzzaman, N. Rahim: Int J Numerical Methods for Heat and Fluid Flow, 29 (2019) 1920-1946.

[6] M. Tawk, Y. Avenas, A. Kedous-Lebouc, D. Charalampous, E. Dubois, J. Chevalet, "Etude d'un système de refroidissement de composants électroniques de puissance par métal liquide," 13ème édition de la Conférence - Électronique de Puissance du Futur (EPF), Saint-Nazaire, France Jun 2010.

[7] C. Qi, Y.L. Wan, G.Q. Wang, D.T. Han: Indian J Physics, 92 (2018) 461-478.

[8] X. Wang, Z. Wan, Y. Tang: J Physics of Fluids, 30 (2018) 027102.

[9] D.B. Tuckerman, R.F.W. Pease: IEEE Electron Device Letters, EDL, 2 (1981) 126-129.

[10] H.Y. Wu, P. Cheng: Int J Heat Mass Transfer, 46 (2003) 2519-2525.

[11] C. Nonino, S. Savino, S. Del Giudice: Int J Numerical Methods for Heat Fluid Flow, 25 (2015) 1322-1339.

[12] E. Belahmadi, R. bessaih: World J Engineering, 15 (2018) 604-613.

[13] S. S. Khaleduzzaman, R Saidur, J. Selvaraj, I.M. SohelMahbubul, M.R. Sohel, I.M Shahrul: Advanced Materials Research, 832 (2014) 218-223.

[14] A.A. Abed, W.H. Khalil: Al-Nahrain University, College of Engineering J (NUCEJ), 91(2016) 66-75.

[15] I. Gherasim, G. Roy, C.T. Nguyen, D. Vo-Ngoc: Int J Thermal Sciences, 50 (2011) 369-377.

[16] A. Khanlari, A. Sözen, H.İ. Variyenli: Int J Numerical Methods for Heat Fluid Flow, 29 (2018) 1343-1362.

[17] S. Kumar, K. S. Pawan: Int J Thermal Sci, 138 (2019) 504-511.

[18] M. Bezaatpour, M. Goharkhah: Powder Technology, 344 (2019) 68-78.

[19] M. Saeed, M. Kim: Int J Heat Mass Transfer, 120 (2018) 671- 682.

[20] R. Ramin, P. Nader, A. Soheil: Int J Thermal Sciences, 132(2018) 76-85.

[21] F. Stéphane, P. Guillaume, P. Catalin, "Nanofluides et transfert de chaleur par convection naturelle" Journée Thématique SFT - Paris, 15 mars 2012.

[22] F. O. Hakan, E. Abu-Nada: Int J Heat Fluid Flow, 29 (2008) 1326-1336. 
[23] K. Khanafer, K. Vafai, M Lightstone: Int J Heat and Mass Transfer, 46(2003) 3639-3653.

[24] T-Ch. Hung, W-M. Yan, X-D. Wang, C-Y. Chang: Int J Heat Mass Transfer, 55 (2012) 2559-2570.

[25] I. Zakaria, W.A.N.W. Mohamed, A.M.I.B. Mamat, A.M.I Bin, R. Saidur, W.H. Azmi, R. Mamat, K.I. Sainan, H. Ismail: Energy Procedia, 79 (2015) 259-264.

[26] K.M. Mostafa, M.A. Reza, I. Ali: Int Commun Heat Mass Transfer, 40 (2013) 5866.

[27] D.D. Ma, G.D. Xia, Y.F. Li, Y.T. Jia, J. Wang: Energy Conversion Management, 127 (2016) 160-169.

(c) (i) Creative Commons License

This work is licensed under a Creative Commons Attribution 4.0 International License. 